Rev. Bras. Saúde Prod. Anim., Salvador, v.14, n.4, p.624-634 out./dez., 2013 http://www.rbspa.ufba.br ISSN 15199940

\title{
Produção e composição química de híbridos de sorgo e de milho para silagem
}

\author{
Production and chemical composition of hybrid sorghum and corn for silage
}

\author{
MORAES, Sheilla Davoglio de ${ }^{1^{*}}$; JOBIM, Clóves Cabreira'; SILVA, Michele Simili da'; \\ MARQUARDT, Fabiany Izabel ${ }^{1}$
}

\footnotetext{
${ }^{1}$ Universidade Estadual de Maringá, Programa de Pós-Graduação em Zootecnia, Maringá, Paraná, Brasil. *Endereço para correspondência: sheillazoo@hotmail.com
}

\section{RESUMO}

Objetivou-se avaliar os parâmetros produtivos e a composição química de quatro híbridos de sorgo (XBS 60015, XBS 60451, Dow F305 e AG 2005E), e de um híbrido de milho (AS32). $\mathrm{O}$ delineamento experimental utilizado foi em blocos completos casualizados com três repetições. Foram avaliadas as produções totais de massa verde (MV), massa seca (MS) e das frações colmo, folha, panícula, espiga (milho). Determinaram-se os teores de proteína bruta (PB), fibra em detergente neutro (FDN), fibra em detergente ácido (FDA), extrato etéreo (EE), carboidratos totais (CHOT), carboidratos não estruturais (CNE), matéria mineral (MM) e matéria orgânica (MO) da planta e das frações folha e panícula. Não houve diferença entre os híbridos para produção de MS, MV e folha. Para a composição química das plantas de sorgo e milho houve diferença entre os híbridos, sendo que para proteína bruta, o sorgo AG 2005E apresentou a maior média com $9,84 \%$, e o milho AS32 a menor, com $7,76 \%$. Para a composição das folhas, a PB foi menor nos híbridos XBS $60015(9,8 \%)$ e XBS 60451 (9,87\%), com maiores concentrações de FDN, 66,02 e $66,65 \%$, respectivamente. As panículas dos sorgos tiveram as maiores médias de $\mathrm{PB}$ $(10,06 \%)$ em relação à espiga do milho $(7,78 \%)$. O CNE foi maior para as panículas de XBS 60015 com 29,61\% e XBS 60451 com 27,20\%. Os híbridos de sorgo apresentaram uma melhor qualidade em sua composição química, sendo recomendável sua utilização para produção de silagens de qualidade.

Palavras-chave: carboidratos totais, massa de forragem, panícula, proteína bruta

\section{SUMMARY}

The goal in this research was to evaluate the production parameters and chemical composition of four sorghum hybrids (60015 XBS, XBS 60451, AG and Dow 2005 F305 E) and a corn hybrid (AS32).In the experimental design was used complete blocks randomized with three repetitions. It was evaluated the total production of green mass (MV), dry matter (MS) and the stem, leaf, panicle, spike (maize). It was determined the content of crude protein (PB), neutral detergent fiber (FDN), acid detergent fiber (FDA), ether extract (EE), total carbohydrates (CHOT), non-fiber carbohydrates $(\mathrm{CNF})$, mineral matter (MM) and organic matter (MO) of the plant, leaf fractions and panicle. There was no production difference between hybrids DM, MV and leaf. In the chemical composition of sorghum and maize plants, there were some differences among the hybrids. The crude protein, sorghum AG $2005 \mathrm{E}$ had the highest average with $9.84 \%$, and corn AS32 had the smallest one, with $7.76 \%$. For the leaves composition, the $\mathrm{PB}$ was smaller in the hybrids XBS $60015(9,8 \%)$ and XBS $60451(9,87 \%)$, higher concentrations of FDN, 66,02 and $66,65 \%$, respectively. The sorghum panicles had higher average of PB $(10,06 \%)$ in relation to the corn $(7,78 \%)$. The CNE was higher than the panicles of XBS 60015 with $29,61 \%$ and XBS 60451 with $27,20 \%$. The sorghum hybrids presented a better quality in their chemical composition. So it is recommended their utilization to make better quality silage.

Keywords: crude protein, forage mass, panicle, total carbohydrates, 


\section{INTRODUÇÃOO}

A ensilagem tem como objetivo manter a qualidade e o valor nutricional da forragem fresca. Deste modo, é importante considerar que são vários os fatores que influenciam na conservação da forragem, resultando numa silagem de boa ou de má qualidade.

Atualmente, existe um grande número de híbridos de milho e sorgo recomendados para a produção de silagem. Provavelmente, o milho é uma das espécies mais cultivadas e com grande diversidade com relação à produção de matéria verde, produção de grãos, folhas e colmo interferindo no valor nutricional da silagem como produto final. A composição das frações da planta também afeta o resultado da silagem. Assim, na produção de uma boa silagem de milho, deve-se considerar além do percentual de grãos na massa ensilada e a alta produtividade de biomassa, a participação das demais frações da planta, com ênfase na digestibilidade da fibra em detergente neutro das mesmas (ZOPOLLATTO \& RECO, 2009).

O sorgo (Sorghum bicolor (L.) Moench) apresenta-se como uma alternativa ao milho, por ser adaptada ao processo de ensilagem, em virtude de suas características fenotípicas, as quais determinam facilidade de semeadura, manejo, colheita e armazenamento, aliadas ao alto valor nutritivo e concentração de carboidratos solúveis, essenciais para uma adequada fermentação lática, bem como aos rendimentos significativos de massa seca por unidade de área (NEUMANN et al., 2002; CHIEZA et al., 2008).

A cultura do sorgo visando à produção de silagem destaca-se principalmente em regiões que apresentam particularidades edafoclimáticas que limitam o cultivo ou o potencial produtivo da cultura do milho, principalmente no período da entressafra (NEUMANN et al., 2005).

Existem diversos híbridos de sorgo atualmente no mercado, porém nem todos são adequados para produzir silagem de qualidade. A digestibilidade do colmo, qualidade dos grãos, resistência a doenças, adaptabilidade ao ambiente e produção de matéria seca são fatores que afetam a qualidade da silagem e o desempenho animal (REZENDE et al., 2011).

Desta forma é valido considerar que para produzir silagem com boa qualidade, seja de milho ou sorgo, devem ser levados em consideração não somente a produção de massa e o percentual de grãos no material ensilado, mas também os demais componentes da planta como um todo, bem como a sua composição química.

\section{MATERIAL E MÉTODOS}

O trabalho foi desenvolvido com as avaliações de campo conduzidas na Estância JAE, no município de Santo Inácio-PR, no ano agrícola de 2009, em cultivo de safrinha (plantio no mês de março e colheita no mês de julho). As análises laboratoriais foram realizadas no Laboratório de Análises de Alimentos e Nutrição Animal do Departamento de Zootecnia da Universidade Estadual de Maringá. Os dados climáticos podem ser vistos na Figura 1.

Foram avaliados dois híbridos de sorgo em desenvolvimento para produção de silagem pela Monsanto do Brasil (Sorgo XBS 60015 e Sorgo XBS 60451), tendo como referência os híbridos comerciais de sorgo disponíveis no mercado (AG 2005E e F305) e um híbrido de milho (AS32), totalizando cinco tratamentos. O híbrido DOW F305 é classificado 
como forrageiro, enquanto os híbridos AG 2005 E, XBS 60451 e XBS 60015 são classificados de duplo propósito, ou seja, produção de forragem e grãos. As culturas foram estabelecidas em parcelas de seis linhas distanciadas em $0,7 \mathrm{~m}$, obedecendo à população de plantas recomendada para cada material, sendo 60mil plantas/ha para o milho e cerca de $240 \mathrm{mil}$ plantas/ha para os sorgos. O plantio foi em parcelas com dimensões de 4,2 x 10m (42 $\left.\mathrm{m}^{2}\right)$, sendo quatro parcelas para cada material, totalizando aproximadamente $1.000 \mathrm{~m}^{2}$, incluindo as áreas $(1,0 \mathrm{~m}) \mathrm{de}$ ruas entre parcelas.

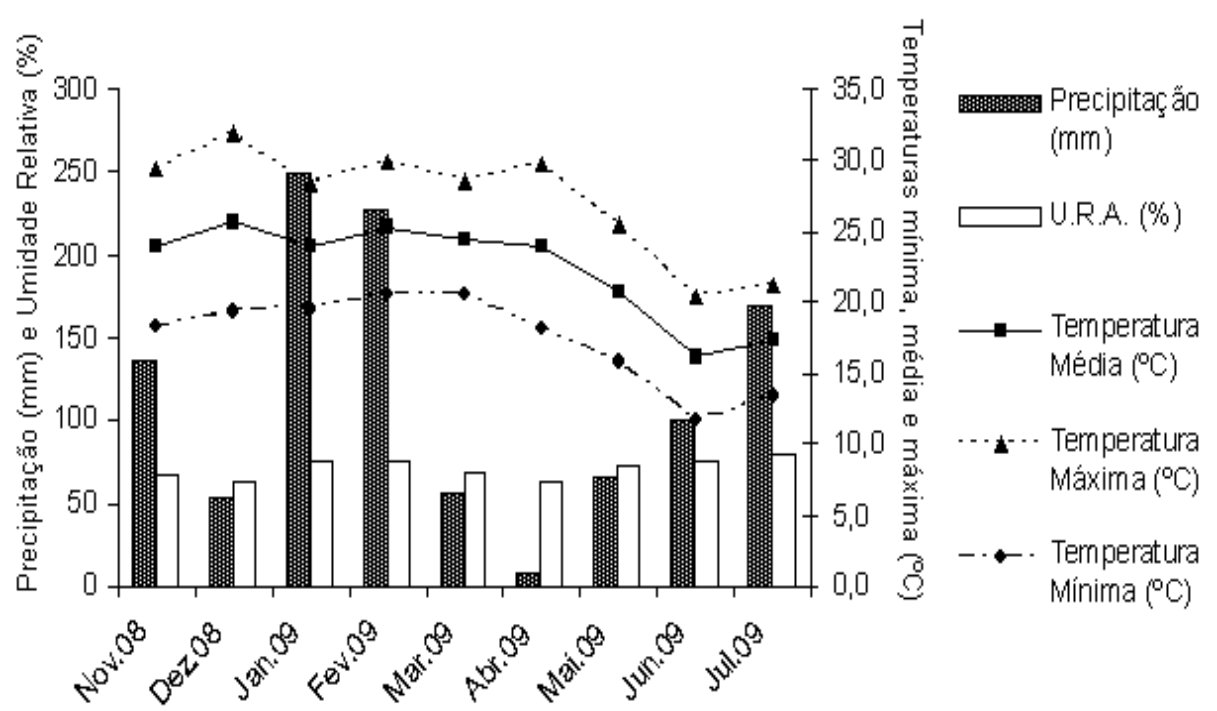

Fonte: Precipitação: Estância JAE - Temperatura/Umidade: Iapar - Paranavaí, Estado do Paraná.

Figura 1. Dados climáticos observados durante o período experimental (novembro de 2008 a julho de 2009)

As adubações na semeadura e em cobertura foram realizadas de acordo com a análise de solo. Foram aplicados 300kg de Super Fosfato Simples e $176 \mathrm{~kg}$ de Cloreto de Potássio no plantio e $80 \mathrm{~kg}$ de Nitrogênio, tendo como fonte a ureia em cobertura numa única aplicação. Os tratos culturais foram realizados conforme recomendações técnicas e aplicação de defensivos, quando necessário, realizados conforme recomendação dos fabricantes.

No dia de corte para ensilagem, foram amostradas cinco plantas por parcela para separação dos componentes estruturais. Para todos os materiais foi determinada a produção de colmo, folha, panícula $($ sorgo $=$ cacho, milho $=$ pendão), espiga (milho), e a produção total de massa verde ( $\mathrm{kg} / \mathrm{ha})$ e de massa seca (kg/ha) com cortes nos estádios recomendados para produção de silagem. Após a pesagem do material fresco, as amostras da planta inteira e das frações foram secas a $55^{\circ} \mathrm{C}$ por $72 \mathrm{~h}$ em estufa com circulação forçada de ar e moídas em moinho tipo "Willey" com peneira de $1 \mathrm{~mm}$ de malha para análises químicas. Das amostras foram determinados os teores de matéria seca (MS), matéria verde (MV), proteína bruta $(\mathrm{PB})$, extrato etéreo (EE), matéria orgânica (MO) e matéria mineral (MM), obtidos segundo citado por Silva \& Queiroz (2002). A determinação da fibra em detergente neutro (FDN), fibra 
em detergente ácido (FDA) foram obtidas de acordo com Van Soest et al. (1991). Os valores de carboidratos totais (CHOT) e carboidratos não fibrosos (CNE) foram calculados, segundo Sniffen et al. (1992), em que: $\mathrm{CHO}=$ $100-(\% \mathrm{~PB}+\% \mathrm{EE}+\% \mathrm{CINZAS}) \mathrm{e}$ $\mathrm{CNE}=\mathrm{CHO}-\mathrm{FDN}$.

Os tratamentos foram distribuídos em delineamento de blocos completos casualizados com quatro repetições. Os dados foram analisados, segundo $\mathbf{o}$ modelo:

$Y_{i j}=u+t_{i}+b_{j}+e_{i j}$

Em que: $Y_{i j}=$ observação do tratamento i na repetição $j ; \quad u=$ média $\operatorname{dos}$ tratamentos; $t_{i}=$ efeito do tratamento $i ; i$ $=1$ a $5 ; b_{j}=$ efeito de bloco $j ; \mathrm{j}=1$ a 4 ; $e_{i j}=$ erro aleatório associado a cada observação $Y_{i j}$. As diferenças entre as médias foram comparadas utilizando o teste de Tukey a 5\%.

\section{RESULTADOS E DISCUSSÃO}

Foi constatado na Tabela 1 que apenas para a produção de colmo e de panícula houve diferença significativa $(\mathrm{P}<0,05)$ entre os materiais avaliados.

Apesar das culturas não terem apresentado diferenças significativas $(\mathrm{P}>0,05)$ na produção de massa forrageira, o sorgo XBS 60015 apresentou maior produção de $\mathrm{MS}$, e o milho a menor produção. O sorgo XBS 60015 apresentou a maior quantidade de folhas $(7,731 \mathrm{t} / \mathrm{ha})$, o que contribuiu efetivamente para produção de MS total.

Tabela 1. Produção de massa de forragem verde (MV), massa de forragem seca (MS), folhas, colmos, panícula e espiga de milho e sorgo colhidos para ensilagem

\begin{tabular}{lcccccc}
\hline Cultura & $\begin{array}{c}\text { MV } \\
(\mathrm{kg} / \mathrm{ha})\end{array}$ & $\begin{array}{c}\text { MS } \\
(\mathrm{kg} / \mathrm{ha})\end{array}$ & $\begin{array}{c}\text { Folha } \\
(\mathrm{kg} / \mathrm{ha})\end{array}$ & $\begin{array}{c}\text { Colmo } \\
(\mathrm{kg} / \mathrm{ha})\end{array}$ & $\begin{array}{c}\text { Panícula } \\
(\mathrm{kg} / \mathrm{ha})\end{array}$ & $\begin{array}{c}\text { Espiga } \\
(\mathrm{kg} / \mathrm{ha})\end{array}$ \\
\hline Milho AS32 & 26.398 & 9.238 & 2.869 & $2.205^{\mathrm{a}}$ & $222^{\mathrm{d}}$ & 3.942 \\
Sorgo AG 2005E & 29.045 & 10.803 & 4.063 & $1.727^{\mathrm{bc}}$ & $5.012^{\mathrm{a}}$ & ---- \\
Sorgo XBS 60015 & 35.655 & 12.767 & 7.731 & $1.824^{\mathrm{b}}$ & $2.799^{\mathrm{b}}$ & ---- \\
Sorgo XBS 60451 & 32.378 & 11.675 & 5.693 & $2.042^{\mathrm{ab}}$ & $3.940^{\mathrm{ab}}$ & ---- \\
Sorgo DowF305 & 29.597 & 9.778 & 5.998 & $1.460^{\mathrm{c}}$ & $2.320^{\mathrm{c}}$ & ---- \\
\hline CV $(\%)$ & 18,99 & 19,75 & 20,67 & 23,31 & 22,32 & ---- \\
\hline
\end{tabular}

Valores seguidos de letras desiguais diferem pelo teste Tukey a 5\%.

$\mathrm{CV}=$ Coeficiente de variação.

A produção de matéria seca dos materiais avaliados foi superior àquelas obtidas por Rezende et al. (2011), quando avaliaram cinco híbridos de sorgo cultivados no inverno. Os autores obtiveram em média 8,7t/ha de MS, provavelmente devido às condições climáticas predominantes no período do inverno, com menores precipitações e baixas temperaturas. Por sua vez
Skonieski et al. (2010), com diferentes híbridos de sorgo forrageiro e de duplo propósito semeados em novembro encontraram valores de $17.527 \mathrm{~kg} / \mathrm{ha}$ e $13.006 \mathrm{~kg} / \mathrm{ha}$ de matéria seca, respectivamente. Estes valores superiores de produção de matéria seca podem ser explicados pela época de cultivo.

Em média, todos os sorgos apresentaram produção de MS/ha acima 
do obtido com o milho AS32 que foi de $9.238 \mathrm{~kg} / \mathrm{ha}$. Estes resultados evidenciam que os materiais de sorgo avaliados são mais indicados para o plantio de safrinha em regiões com baixa precipitação, quando comparados ao milho. Paziani et al. (2009) avaliando diferentes híbridos de milho encontraram valores médios de $50.470 \mathrm{~kg} / \mathrm{ha}$ de matéria verde e $18.693 \mathrm{~kg} / \mathrm{ha}$ de matéria seca. Essa diferença pode ser explicada pelo fato do cultivo do milho, nesse trabalho, ter ocorrido durante o período da safrinha, período que normalmente há estresse hídrico acentuado, proporcionando baixa produção na matéria seca.

A produção de colmo foi superior para o milho AS32 $(2.205 \mathrm{~kg} / \mathrm{ha})$ em relação aos sorgos, com exceção do sorgo XBS $60451 \quad(2.042 \mathrm{~kg} / \mathrm{ha})$. As menores produções de colmo foram obtidas com os sorgos DOW F305 e AG 2005E, os quais também apresentaram produção de massa forrageira inferior $(\mathrm{P}>0,05)$ aos demais sorgos avaliados. De forma geral, a produção de colmos representou $15,64 \%$ em relação à produção total de MS, enquanto que para o milho foi de $23,83 \%$. Híbridos de sorgo de porte alto tem a tendência de apresentarem percentagens maiores de colmo, comprometendo a qualidade do valor nutritivo da forragem.

A maior produção de panícula foi para os sorgos AG 2005E com $5.012 \mathrm{~kg} / \mathrm{ha}$ $(17,26 \%$ na MS) e XBS 60451 com $3.940 \mathrm{~kg} / \mathrm{ha}(12,17 \%$ na MS). Rezende et al. (2011) observaram que a porcentagem de panícula na matéria verde do sorgo AG 2501, considerado de corte e pastejo, foi de 4,66\% na MS, resultado inferior aos obtidos para os híbridos de sorgo forrageiro e de duplo propósito, com 9,59\% na MS. Skoniesk et al. (2010) avaliaram as características produtivas das plantas de sorgo e encontraram valores de produção de panícula para os sorgos de duplo propósito (18,19\% na MS), em relação ao sorgo forrageiro (15,35\% na MS).

O milho apresentou $3.942 \mathrm{~kg} / \mathrm{ha}$ de espigas. É importante ressaltar que quanto maior a quantidade de espigas no material maior será a presença de grãos. No grão está a maior concentração de amido e açúcares solúveis. Desta forma, é desejável uma maior proporção de espigas no material a ser ensilado, pois quanto maior a proporção de grãos presentes, melhor será a qualidade fermentativa e nutricional da silagem. Entretanto, de uma maneira geral, todos os híbridos apresentaram boas proporções de folhas e panículas em relação aos colmos.

$\mathrm{Na}$ Tabela 2 são apresentadas a razão folha/colmo e porcentagem de panícula na matéria seca, onde podem ser observadas diferenças significativas $(\mathrm{P}<0,05)$ para as duas variáveis avaliadas. Não houve diferenças significativas $(\mathrm{P}>0,05)$ para os sorgos $\mathrm{AG}$ 2005E e XBS 60451. Estes genótipos apresentaram a menor razão folha/colmo $(2,35$ e 2,79, respectivamente) e o genótipo AG 2005E, a maior porcentagem de panícula na matéria seca $(46,39)$, o que pode significar forragem de melhor qualidade.

A panícula do sorgo é a parte da planta que apresenta maior digestibilidade, enquanto que os colmos são de menor digestibilidade, por ser a fração da planta com elevados teores de fibras e lignina. Assim, o aumento da participação de grãos tem efeito diluidor do teor de fibra, mesmo este sendo crescente na parte vegetativa da planta. Santos et al. (2013), em estudo das características agronômicas de cultivares de sorgo obtiveram média de $32,2 \%$ na MS de produção de panícula, valor semelhante ao encontrado neste estudo para o sorgo XBS $60451(33,75 \%)$. Nos resultados encontrados pelos mesmos autores pôde-se observar que quanto maior a 
porcentagem da panícula menor a porcentagem do colmo dos diferentes híbridos avaliados. Rezende et al. (2011) encontraram maior porcentagem de panícula para os híbridos AG 2005E (duplo propósito) e para o sorgo BRS 610 (forrageiro). Para $\mathrm{o}$ primeiro híbrido foi obtido valor de 10,18\% e para o segundo, 10,27\%. Porém, a menor porcentagem de colmo foi de $67,32 \%$ para o sorgo AG 2005E enquanto que o sorgo forrageiro BRS 610 obteve $76,05 \%$.

Tabela 2. Razão folha/colmo e percentagem de panículas em sorgos colhidos para ensilagem

\begin{tabular}{lcc}
\hline Cultura & $\begin{array}{c}\text { Razão } \\
\text { Folha/colmo }\end{array}$ & Panícula na MS $(\%)$ \\
\hline Sorgo AG 2005E & $2,35^{\mathrm{b}}$ & $46,39^{\mathrm{a}}$ \\
Sorgo XBS 60015 & $4,24^{\mathrm{a}}$ & $21,93^{\mathrm{c}}$ \\
Sorgo XBS 60451 & $2,79^{\mathrm{b}}$ & $33,75^{\mathrm{b}}$ \\
Sorgo Dow F305 & $4,11^{\mathrm{a}}$ & $23,73^{\mathrm{c}}$ \\
\hline CV $(\%)$ & 9,05 & 13,21 \\
\hline
\end{tabular}

Valores seguidos de letras desiguais diferem pelo teste Tukey a 5\%.

$\mathrm{CV}=$ Coeficiente de variação.

Em relação à composição química das plantas no momento da ensilagem (Tabela 3), verificou-se que houve diferenças significativas $(\mathrm{P}<0,05)$ entre os materiais avaliados. Para a variável $\mathrm{PB}$, os maiores valores encontrados foram para os sorgos AG $2005 \mathrm{E}$ $(9,84 \%)$, DOW F305 $(9,51 \%)$ e XBS 60015 (8,85\%). O sorgo AG 2005E, apesar da baixa participação de folhas em relação aos outros híbridos, apresentou valor de proteína relevante, o que pode ser atribuído à sua melhor contribuição de panícula na planta. Os valores para PB observados neste presente estudo foram maiores que os valores encontrados no trabalho de Oliveira et al. (2010), na avaliação da composição química de diferentes forrageiras, no sorgo-sudão obtiveram $6,8 \%$ e $5,5 \%$ para sorgo forrageiro.

Há dois tipos de carboidratos nas plantas que são encontrados no conteúdo celular e na parede celular: carboidratos estruturais e não estruturais. Os carboidratos estruturais encontrados na parede celular são a celulose, hemicelulose e lignina, e os carboidratos não estruturais que são encontrados no conteúdo celular são principalmente o amido e açúcares solúveis em água. Os açúcares solúveis são de vital importância na preservação da forragem ensilada. Quando a planta ou parte dela tem alto conteúdo de parede celular, especialmente lignina, como no caso do colmo, a digestibilidade é baixa e o desempenho animal é reduzido.

O sorgo XBS 60015 obteve a menor porcentagem de FDN (55,57\%) em relação aos demais sorgos e milho $(\mathrm{P}<0,05)$. Para a variável FDA houve diferenças significativas $\quad(\mathrm{P}<0,05)$ apenas entre o milho e o híbrido AG 2005E, 28,87 e $38,6 \%$, respectivamente. As frações FDN e FDA quando em níveis elevados, acima dos valores obtidos, comprometem o consumo e o aproveitamento da forragem. A fração FDN tem relação negativa com $\mathrm{o}$ 
consumo, visto que é um fator físico que limita a ingestão de matéria seca, enquanto que as frações FDA e lignina possuem relação negativa com a digestibilidade aparente do material e com a ingestão (LUPATINI et al., 2004). Segundo Vasconcelos et al. (2005), quanto menor o valor de FDA, maior o valor energético do alimento.

Tabela 3. Composição química (\% da MS) das plantas no momento da ensilagem

\begin{tabular}{llllllll}
\hline Cultura & PB & FDN & FDA & EE & CNE & MM & MO \\
\hline Milho AS32 & $7,76^{\mathrm{c}}$ & $62,74^{\mathrm{a}}$ & $28,87^{\mathrm{b}}$ & $1,49^{\mathrm{bc}}$ & $23,88^{\mathrm{b}}$ & 4,13 & 95,87 \\
Sorgo AG 2005E & $9,84^{\mathrm{a}}$ & $66,65^{\mathrm{a}}$ & $38,60^{\mathrm{a}}$ & $1,98^{\mathrm{ab}}$ & $15,55^{\mathrm{c}}$ & 5,98 & 94,02 \\
Sorgo XBS 60015 & $8,85^{\mathrm{abc}}$ & $55,57^{\mathrm{b}}$ & $31,00^{\mathrm{ab}}$ & $2,36^{\mathrm{a}}$ & $29,09^{\mathrm{a}}$ & 4,13 & 95,87 \\
Sorgo XBS 60451 & $8,27^{\mathrm{bc}}$ & $64,23^{\mathrm{a}}$ & $31,54^{\mathrm{ab}}$ & $1,44^{\mathrm{bc}}$ & $21,99^{\mathrm{b}}$ & 4,07 & 95,93 \\
Sorgo Dow F305 & $9,51^{\mathrm{ab}}$ & $61,72^{\mathrm{a}}$ & $30,63^{\mathrm{ab}}$ & $2,42^{\mathrm{a}}$ & $21,04^{\mathrm{b}}$ & 5,31 & 94,69 \\
\hline CV $(\%)$ & 8,45 & 10,57 & 10,34 & 9,47 & 9,32 & 8,59 & 8,56 \\
\hline
\end{tabular}

Valores seguidos de letras desiguais diferem pelo teste Tukey a 5\%.

$\mathrm{CV}=$ Coeficiente de variação.

Skoniesk et al. (2010), trabalhando com híbridos de sorgo para produção de silagem, encontraram teor médio de FDN $(55,54 \%)$ inferior aos obtidos neste trabalho, o qual apresentou valores médios de $62,18 \%$ na MS. Por sua vez, Rezende et al. (2011) encontraram médias de FDN de $60 \%$ para o milho, 61,8\% para o sorgo-sudão e 56,9\% para o sorgo forrageiro, enquanto para o FDA obtiveram 39,2, 46,2 e $41,1 \%$, respectivamente.

Os híbridos de sorgo que apresentaram os maiores valores para $\mathrm{EE}$ foram $\mathrm{O}$ XBS 60015 e o DOW F305 com 2,36 e $2,42 \%$, respectivamente. Chieza et al. (2008), quando trabalharam com híbridos de sorgo,encontraram 3,89\% de EE no híbrido AG 2005E, enquanto no presente estudo foi obtido para o mesmo híbrido 1,98\% na MS.

Os níveis de carboidratos não estruturais estão condizentes com os níveis de FDN e FDA encontrados nos materiais, já que a menor percentagem de carboidratos não estruturais foi encontrada no sorgo AG 2005E, com $15,55 \%$. Os maiores teores de CNE foram obtidos no sorgo XBS 60015, com 29,09\%, indicando uma boa participação de amido e açúcares solúveis em água, sendo uma importante característica que se busca nas plantas destinadas à produção de silagens. Apesar do sorgo DOW F305 ser classificado como sorgo forrageiro, diferente dos demais híbridos aqui estudados, tendo outras características tais como: um porte mais alto $\mathrm{e}$ consequentemente resultando em maiores quantidades de carboidratos estruturais, o resultado mostrou-se semelhante ao híbrido XBS 60451 de duplo propósito, com $21,04 \%$ de CNE. Os valores para matéria mineral foram semelhantes e sem diferença $(\mathrm{P}>0,05)$ entre os materiais avaliados. $\mathrm{O}$ mesmo comportamento foi observado para os teores de MO. Os teores de MM e de MO observados nesse estudo estão de acordo com os teores encontrados por Chieza et al. (2008).

A composição química das folhas (Tabela 4) apresentou diferenças significativas $(\mathrm{P}<0,05)$ entre o milho $\mathrm{e}$ os híbridos de sorgo para PB, FDN, 
FDA e EE. O teor de PB na folha do milho, dos sorgos AG 2005E e DOW F305 foi superior $(\mathrm{P}<0,05)$ em relação aos demais híbridos avaliados. O sorgo AG 2005E foi o híbrido que apresentou a menor percentagem de folhas na planta, entretanto mostrou elevado teor de proteína nas folhas $(12,05 \%)$. Para a fração FDN, as folhas dos híbridos de sorgo XBS 60015 e XBS 60451 apresentaram valores semelhantes ao observado nas folhas do milho, com valor médio de $65,14 \%$. O mesmo comportamento foi observado para o teor de FDA, com diferença $(\mathrm{P}<0,05)$ somente entre os sorgos AG 2005E e XBS 60015.

Tabela 4. Composição química (\% da MS) das folhas no momento da ensilagem

\begin{tabular}{lclllllll}
\hline Cultura & PB & FDN & FDA & EE & CHOT & CNE & MO & MM \\
\hline Milho AS32 & $12,16^{\mathrm{a}}$ & $62,90^{\mathrm{ab}}$ & $32,21^{\mathrm{ab}}$ & $1,56^{\mathrm{b}}$ & 79,30 & 16,40 & 93,02 & 6,98 \\
Sorgo AG 2005E & $12,05^{\mathrm{a}}$ & $62,25^{\mathrm{b}}$ & $30,99^{\mathrm{b}}$ & $3,37^{\mathrm{a}}$ & 78,36 & 16,11 & 93,78 & 6,22 \\
Sorgo XBS 60015 & $9,80^{\mathrm{b}}$ & $66,02^{\mathrm{a}}$ & $35,69^{\mathrm{a}}$ & $3,09^{\mathrm{a}}$ & 81,32 & 15,30 & 94,21 & 5,79 \\
Sorgo XBS 60451 & $9,87^{\mathrm{b}}$ & $66,65^{\mathrm{a}}$ & $33,26^{\mathrm{ab}}$ & $2,51^{\mathrm{ab}}$ & 82,27 & 16,62 & 94,65 & 5,35 \\
Sorgo DowF305 & $13,55^{\mathrm{a}}$ & $65,65^{\mathrm{ab}}$ & $34,42^{\mathrm{ab}}$ & $3,54^{\mathrm{a}}$ & 77,44 & 11,79 & 94,53 & 5,47 \\
\hline CV $(\%)$ & 9,48 & 11,89 & 10,02 & 14,35 & 13,04 & 11,87 & 9,43 & 9,52 \\
\hline
\end{tabular}

Valores seguidos de letras desiguais diferem pelo teste Tukey a 5\%.

$\mathrm{CV}=$ Coeficiente de variação.

Gomes et al. (2006) avaliaram 11 híbridos de sorgo e encontraram na fração folha $6,31 \%$ de PB, 63,34\% de FDN e $35,35 \%$ de FDA, em média. No presente trabalho, para a fração folha foram encontrados $11,48 \%$ de $\mathrm{PB}$, $64,69 \%$ de FDN e $33,31 \%$ de FDA em média. Estas características podem ser associadas às diferentes cultivares disponíveis no mercado.

O milho AS32 apresentou a menor concentração de EE na fração folha $(1,56 \%)$, sem diferir $(\mathrm{P}>0,05)$ do híbrido XBS 60451, enquanto que os demais sorgos não evidenciaram diferença significativa $(\mathrm{P}>0,05)$ com valor médio de $3,12 \%$.

Os carboidratos totais (CHOT) não mostraram efeitos significativos $(\mathrm{P}>0,05)$, entre os materiais avaliados. $\mathrm{O}$ mesmo comportamento foi observado para as variáveis $\mathrm{CNE}$, MO e MM.

Considerando essas concentrações de carboidratos não estruturais nas folhas, o milho foi a planta que teve a menor produção de folhas em relação aos híbridos de sorgo (Tabela 5), porém obteve resultado igual de CNE em relação aos mesmos.

Os valores referentes à composição química das panículas (inflorescência masculina $=$ pendão) do milho AS32 e de híbridos de sorgo mostraram diferenças significativas $(\mathrm{P}<0,05)$ para as variáveis PB, FDN, FDA e CNE. A menor concentração de $\mathrm{PB}$ na panícula foi encontrada no milho, com 7,78\%, enquanto que os híbridos de sorgo apresentaram valores em média de $10,06 \%$, o que é explicado pela presença dos grãos na panícula dos sorgos. O milho e os híbridos AG 2005E e DOW F305 não apresentaram diferença $(\mathrm{P}>0,05)$ para a fração FDN, enquanto os híbridos XBS 60015 e XBS 60451 apresentaram os menores teores. 
Rev. Bras. Saúde Prod. Anim., Salvador, v.14, n.4, p.624-634 out./dez., 2013 http://www.rbspa.ufba.br ISSN 15199940

Tabela 5. Composição química (\% da MS) das panículas no momento da ensilagem

\begin{tabular}{lclllllll}
\hline Cultura & PB & FDN & FDA & EE & CHOT & CNE & MO & MM \\
\hline Milho AS32 & $7,78^{\mathrm{b}}$ & $67,54^{\mathrm{a}}$ & $22,91^{\mathrm{ab}}$ & 2,28 & 87,87 & $20,33^{\mathrm{b}}$ & 97,93 & 2,07 \\
Sorgo AG 2005E & $10,01^{\mathrm{a}}$ & $63,90^{\mathrm{a}}$ & $20,27^{\mathrm{b}}$ & 3,82 & 82,34 & $18,44^{\mathrm{b}}$ & 96,17 & 3,83 \\
Sorgo XBS 60015 & $9,99^{\mathrm{a}}$ & $54,93^{\mathrm{a}}$ & $24,39^{\mathrm{ab}}$ & 2,33 & 84,54 & $29,61^{\mathrm{a}}$ & 96,86 & 3,14 \\
Sorgo XBS 60451 & $10,06^{\mathrm{a}}$ & $57,29^{\mathrm{b}}$ & $23,00^{\mathrm{ab}}$ & 2,39 & 84,49 & $27,20^{\mathrm{a}}$ & 96,94 & 3,06 \\
Sorgo DowF305 & $10,20^{\mathrm{a}}$ & $65,61^{\mathrm{a}}$ & $26,06^{\mathrm{a}}$ & 2,36 & 83,96 & $18,35^{\mathrm{b}}$ & 95,52 & 3,48 \\
\hline CV $(\%)$ & 10,92 & 12,87 & 10,65 & 9,68 & 11,28 & 9,45 & 8,96 & 16,32 \\
\hline
\end{tabular}

Valores seguidos de letras desiguais diferem pelo teste Tukey a $5 \%$.

$\mathrm{CV}=$ Coeficiente de variação.

Os híbridos de sorgo e o milho AS32 apresentaram diferenças significativas $(\mathrm{P}<0,05)$ nos teores de FDA da panícula, com valores percentuais entre 26,06 para o DOW F305 e 20,27 para o AG 2005E, os quais apresentaram a menor e a maior produção de panícula, respectivamente. Com esse resultado, pode-se afirmar que a maior concentração de panícula dilui a fração fibra do material, tornando esse mais digestível.

Os valores de extrato etéreo, carboidratos totais, matéria orgânica e matéria mineral das panículas não mostraram diferenças significativas $(\mathrm{P}>0,05)$. Para os carboidratos totais, $\mathrm{O}$ maior teor foi observado no milho $(87,87 \%)$, enquanto que os valores foram semelhantes entre os híbridos de sorgo, não havendo efeito significativo $(\mathrm{P}>0,05)$. Os sorgos XBS 60015 e XBS 60451 apresentaram os maiores teores de CNE na panícula, apesar de terem apresentado uma das menores produções de panícula, o que evidencia a qualidade da panícula em sua composição.

Não há diferenças entre os híbridos quanto à produtividade total de massa verde e massa seca. As diferenças são notadas para a produção de colmo e panículas. Os sorgos XBS 60015 e XBS 60451 compensaram por produzir boa quantidade de matéria verde e matéria seca, sendo assim considerados como boas opções para cultivo durante a safrinha, por se adaptarem bem a estas condições.

O híbrido AG 2005E foi o sorgo que mais teve destaque quanto à sua composição bromatológica e níveis de produção, que apesar de ter obtido a menor produção de folhas, compensou com a relevante produção de panículas, o que lhe conferiu boas características para a confecção de silagens de alto valor nutritivo.

\section{REFERÊNCIAS}

CHIEZA, E.D.; ARBOITTE, M.Z.; BRONDANI, I.L.; MENEZES, L.F. G.; RESTLE, J.; SANTI, M.A.M. Aspectos agronômicos de híbridos de sorgo (Sorghum bicolor L. Moench) no desempenho e economicidade de novilhos confinados. Acta Scientiarum. Animal Sciences, v.30, n.1 p.67-73, 2008.

GOMES, S.O.; PITOMBEIRA, J.B.; NEIVA, J.N.M.; CANDIDO, M.J.D. Comportamento Agronômico e composição químico-bromatológica de cultivares de sorgo forrageiro no Estado do Ceará. Revista Ciência Agronômica, v.37, n.2, p.221-227, 2006. 
LUPATINI, C.G.; MACCARI, M.; ZANETTE, S.; PIACENTINI, E.; NEUMANN, M. Avaliação do desempenho agronômico de híbridos de milho (Zea mays, L), para produção de silagem. Revista Brasileira de Milho e Sorgo, v.3, n.2, p.193-203, 2004.

NEUMANN, M.; RESTLE, J.; ALVES FILHO, D.C.; BRONDANI, I.L.; PELLEGRINI, L.G.; FREITAS, A.K. Avaliação do valor nutritivo da planta e da silagem de diferentes híbridos de sorgo (Sorghum bicolor, L. Moench).

Revista Brasileira de Zootecnia, v.31, n.1, p.293-301, 2002. Supl. especial.

NEUMANN, M.; RESTLE, J.;

BRONDANI, I.L. Efeito do tamanho da partícula e do tipo de silo sobre o valor nutritivo da silagem de sorgo (Sorghum bicolor, L. Moench). Revista

Brasileira de Milho e Sorgo, v.4, n.2, p.224-242, 2005.

OLIVEIRA, L.B.; PIRES, A.J.V., VIANA, A.E.S.; MATSUMOTO, S.N.; CARVALHO, G.G.P.; RIBEIRO, L.S.O. Produtividade, composição química e características agronômicas de diferentes forrageiras. Revista Brasileira de Zootecnia, v.39, n.12, p.2604-2610, 2010.

PAZIANI, S.F.; DUARTE, A.P.; NUSSIO, L.G.; GALLO, P.G.; BITTAR, C.M.M.; ZOPOLLATTO, M.; RECO, P.C. Características agronômicas e bromatológicas de híbridos de milho para produção de silagem. Revista Brasileira de Zootecnia, v.38, n.3, p.411-417, 2009.

REZENDE, G.M.; PIRES, D.A.A.; BOTELHO, P.R.F.; ROCHA JÚNIOR, V.R.; SALES, E.C.J.; JAYME, D.G.; REIS, S.T.; PIMENTEL, L.R.; LIMA, L.O.B.; KANEMOTO, E.R.; MOREIRA, P.R. Características agronômicas de cinco genótipos de sorgo [Sorghum bicolor (L.) Moench], cultivados no inverno, para a produção de silagem. Revista Brasileira de Milho e Sorgo, v.10, n.2, p.171-179, 2011.

SANTOS, R.D.; PEREIRA, L.G.R.; NEVES, A.L.A.; RODRIGUES, J.A.S.; COSTA, C.T.F.; OLIVEIRA, G.F. Agronomic characteristics of forage sorghum cultivars for silage production in the lowe rmiddle San Francisco Valley. Acta Scientiarum. Animal Sciences, v.35, n.1, p.13-19, 2013.

SILVA, J.D.; QUEIROZ, A.C. Análise de alimentos: métodos químicos e biológicos. 3.ed. Viçosa, MG: Universidade Federal de Viçosa, 2002. $235 \mathrm{p}$.

SKONIESKI, F.R.; NORNBERG, J.L.; AZEVEDO, E.B. de; DAVID, D.B.; KESSLER, J.D.; MENEGAZ, A.L. Produção, caracterização nutricional e fermentativa de silagens de sorgo forrageiro e sorgo duplo propósito. Acta Scientiarum. Animal Science, v.32, n.1, p.27-32, 2010.

SNIFFEN, C.J.; O'CONNOR, J.D.; Van SOEST, P. J.A net carbohydrate and protein system for evaluating cattle diets; II. Carbohydrate and protein availability. Journal of Animal Science, v.70, n.7, p.3562-3577, 1992.

Van SOEST, P.J.; ROBERTSON, J.B.; LEWIS, B.A. Methods for dietary fiber, neutral detergent fiber, and nonstarch polysaccharides in relation to animal nutrition. Journal of Dairy Science, v.74, n.10, p.3583-3597, 1991.

VASCONCELOS, R.C.; PINHO, R.G.V.; REZENDE, A.V.; PEREIRA, M.N.; BRITO, A.H. Efeito da altura de corte das plantas na produtividade da 
Rev. Bras. Saúde Prod. Anim., Salvador, v.14, n.4, p.624-634 out./dez., 2013 http://www.rbspa.ufba.br ISSN 15199940

matéria seca e em características

bromatológicas da forragem de milho.

Ciência a Agrotecnologia, v.29, n.6, p.1139-1145, 2005.

ZOPOLLATTO, M.; NUSSIO, L.G.;

MARI, L.J.; SCHMIDT, P.; DUARTE,

A.P.; MOURÃO, G.B. Alterações na composição morfológica em função do estádio de maturação em cultivares de milho para produção de silagem.

Revista Brasileira de Zootecnia, v.38, n.3, p.452-461, 2009.

Data de recebimento: $15 / 05 / 2013$

Data de aprovação: 18/11/2013 